\title{
A mini-review of contemporary diagnosis and management of central venous occlusion
}

\author{
Joshua Altschuler ${ }^{1}$, Matthew Janko ${ }^{1,2 *}$ and Robert I Hacker ${ }^{3}$ \\ ${ }^{1}$ Case Western Reserve University School of Medicine, Cleveland, OH, USA \\ ${ }^{2}$ Division of Vascular Surgery and Endovascular Therapy, University Hospitals Cleveland Medical Center, Cleveland, OH, USA \\ ${ }^{3}$ Division of Vascular Surgery, Mercy Hospital, Toledo, OH, USA
}

\begin{abstract}
Innominate vein occlusion is a common but morbid pathology that occurs most frequently in the setting of repeated vascular catheterization, tunneled dialysis catheters, and implanted cardiovascular devices. There are two major treatment approaches to alleviate this pathology; endovascular therapy and open surgery. Today, angioplasty and stenting are commonly employed for symptomatic patients, with open repair reserved for only severely symptomatic patients. New techniques such as laser recanalization may provide new access and relief options for patients who fail traditional angioplasty and stenting or who are too high risk for open surgery, however the risks and limitations must be considered.
\end{abstract}

\section{Introduction}

Innominate and central venous occlusion (CVO) presents an increasingly common clinical and technical challenge that is associated with significant morbidity and advanced disease. CVO most commonly occurs as a result of endovenous scarring secondary to repeated central venous catheterizations, catheter placement or implanted cardiovascular devices [1-3]. It is often the end stage of a repeated manipulation and scarring cycle that is ultimately mediated by intimal hyperplasia and fibrin sheath development [4].

\section{Diagnostic modalities}

History and physical exam are essential for CVO diagnosis. Duplex ultrasound of the upper extremity should be utilized as it is rapid, noninvasive, and inexpensive, albeit limited by $71 \%$ sensitivity for CVO due to variable experience of the performing technician, depth of central veins, and anatomical structures such as the clavicle [5-6]. CT and MRI angiography are alternative initial imaging studies and are particularly useful for venous evaluation at the level of the first rib or to detect position-dependent obstruction [7]. A recent study in a group of 40 patients with chronic renal failure showed that CT venography yielded a sensitivity and specificity of $88.2 \%$ and $97.5 \%$ respectively in detecting subclavian venous occlusion. Another study by Kim et al. showed that CT venography was equal to digital subtraction venography in its ability to determine the cause of central venous obstruction and better able to evaluate central veins proximal to long segmental obstruction [8]. Nevertheless, catheter-based venography remains a widely used diagnostic approach for CVO with an excellent ability to delineate central venous anatomy from collateral veins [9].

\section{Treatment}

Treatment options used for CVO are dependent upon the etiology of the disease. The use of therapeutic anticoagulation alone has no role for recanalization of this process as the issue remains with the development of scar tissue. Open surgical techniques are limited to few highly morbid operations, including venous bypass and open endovenectomy of the occluded central veins via sternotomy. More recently endovascular interventions, primarily angioplasty, have become the contemporary first-line treatment of CVO. Typical techniques include using back and front ends of guidewires, coaxial support catheters and sheaths, sequential dilations, covered and open cell stents, and sharp needle techniques [10]. Catheter-based thrombolysis is effective for the management of CVO secondary to acute thrombosis, especially when combined with a staged surgical correction of the anatomical etiology for venous compression in the case of PSS [11-13].

The difficulty in recanalizing and maintaining a patent CVO occurs from the process of endothelialization, smooth muscle cell proliferation, and extracellular matrix recrudencence [14]. Percutaneous endovenous angioplasty combined with endoluminal stenting has been demonstrated to have acceptable long-term patency though similarly is plagued by intimal hyperplasia, restenosis, and the need for reintervention [15]. Stent placement is also limited by location of the CVO and is contraindicated especially across the thoracic outlet.

Laser recanalization of $\mathrm{CVO}$ has been described recently with good medium-term patency $[16,17]$. This technique may offer an advantage compared against more traditional recanalization techniques by debulking and allowing for a full-stent expansion. This debulking likely removes or reduces the tissue that is typically responsible for endovenous webs, intimal hyperplasia, and restenosis. Coupled with the use of drug eluting balloons the community anticipates good medium and long-term patency rates when paired with self-expanding stents. CVO recanalization with excimer laser may provide new access options for

${ }^{\star}$ Correspondence to: Matthew Janko, Division of Vascular Surgery and Endovascular Therapy, University Hospitals Cleveland Medical Center, 6th Floor Lakeside Building, 11100 Euclid Avenue, Cleveland, OH 44106, USA, E-mail: matthew.janko@uhhospitals.org

Received: June 12, 2018; Accepted: June 19, 2018; Published: June 22, 2018 
patients who would normally not have been candidates for hemodialysis access on the ipsilateral extremity. It also offers opportunity to preserve and salvage a threatened arteriovenous access [16]. New reports of laser recanalization include transvenous pacemaker insertion in patient with bilateral subclavian vein occlusions and removal of embedded inferior vena cava filters [17]. The potential risk of vessel perforation and death should be considered and thus this procedure may not be appropriate for all patients, thus future study is certainly needed.

\section{Conclusion}

CVO is an uncommon but highly morbid pathology that occurs most frequently in the setting of repeated endovenous catheterization, implanted cardiovascular devices, and hypercoagulable conditions such as malignancy. There are various treatment modalities available to attempt recanalization, including endovascular and open techniques. Today, angioplasty and stenting are commonly employed for early and mid-stage disease with complex recanalization with lasers and stenting of more complex and total occlusive pathology.

\section{References}

1. Kodani T, Mine T, Kishima H, Ashida K, Masuyama T (2015) Spontaneous subclavian venous occlusion before electronic device implantation. Asian Cardiovasc Thorac Ann 23: $530-534$.

2. Hernández D, Díaz F, Rufino M, Lorenzo V, Pérez T, et al. (1998) Subclavian vascular access stenosis in dialysis patients: natural history and risk factors. $J$ Am Soc Nephrol 9: $1507 \mathrm{e} 10$. [Crossref]

3. Mickley V (2006) Central vein obstruction in vascular access. Eur J Vasc Endovasc Surg 2: $439 \mathrm{e} 44$.

4. Hacker RI, Garcia Lde M, Chawla A, Panetta TF (2012) Fibrin sheath angioplasty: a technique to prevent superior vena cava stenosis secondary to dialysis catheters. Int $J$ Angiol 21: 129-134. [Crossref]

5. Sanders RJ, Hammond SL (2005) Subclavian vein obstruction without thrombosis. $J$ Vasc Surg 41: 285-290. [Crossref]
6. Melby SJ, Vedantham S, Narra VR, Paletta GA Jr, Khoo-Summers L, et al. (2008) Comprehensive surgical management of the competitive athlete with effort thrombosis of the subclavian vein (Paget-Schroetter syndrome). J Vasc Surg 47.[Crossref]

7. Thompson RW (2012) Comprehensive management of subclavian vein effort thrombosis. Semin Intervent Radiol 29: 44-51. [Crossref]

8. Kim H, Chung JW, Park JH, Yin YH, Park SH, et al. (2003) Role of CT venography in the diagnosis and treatment of benign thoracic central venous obstruction. Korean $J$ Radiol 4: 146-152. [Crossref]

9. Thompson RW (2012) Comprehensive management of subclavian vein effort thrombosis. Semin Intervent Radiol 29: 44-51. [Crossref]

10. Kamran T, Zaheer K, Khan AA, Khalid M, Akhtar MS (2003) Applications and complications of subclavian vein catheterization for hemodialysis. J Coll Physicians Surg Pak 13: 40-43. [Crossref]

11. Illig KA, Doyle AJ (2010) A comprehensive review of Paget-Schroetter syndrome. $J$ Vasc Surg 51: 1538-1547. [Crossref]

12. Adelman MA, Stone DH, Riles TS, Lamparello PJ, Giangola G, et al. (1997) A multidisciplinary approach to the treatment of Paget-Schroetter syndrome. Ann Vasc Surg 11: 149-154. [Crossref]

13. Doyle A, Wolford HY, Davies MG, Adams JT, Singh MJ, et al. (2007) Management of effort thrombosis of the subclavian vein: today's treatment. Ann Vasc Surg 21: 723-729. [Crossref]

14. Green RM, Rosen R (2008) The management of axillo-subclavian venous thrombosis in the setting of thoracic outlet syndrome. In: Handbook of Venous Disorders (3rd Edition). Gloviczki P (Ed.), Hodder Arnold, London, UK, 292-298.

15. Shoenfeld R, Hermans H, Novick A, Brener B, Cordero P, et al. (1994) Stenting of proximal venous obstructions to maintain hemodialysis access. J Vasc Surg 19: 532538. [Crossref]

16. Rambhia S, Janko M, and Robert I. Hacker, RI (2018) Laser Recanalization of Central Venous Occlusion to Salvage a Threatened Arteriovenous Fistula. Ann Vasc Surg. [Crossref]

17. Worley SJ, Gohn DC, Pulliam RW (2010) Excimer laser to open refractory subclavian occlusion in 12 consecutive patients. Heart Rhythm 7: 634e6. [Crossref]

Copyright: (C2018 Altschuler J. This is an open-access article distributed under the terms of the Creative Commons Attribution License, which permits unrestricted use, distribution, and reproduction in any medium, provided the original author and source are credited. 